y confianza para plasmar algunas de las ideas que tuve, cuando aún no mostraba los vicios de la metodología asociada a la disciplina a la que decidí dedicarme.

A raíz de la clase, Julián y yo iniciamos nuestra amistad fuera de las aulas. A lo largo de los últimos cuatro años, he sido afortunado al gozar de cada una de las conversaciones que hemos tenido independientemente del tema y tono. Su gusto por las matemáticas y el mío por las humanidades han hecho que reevalúe varios de mis puntos de vista. Algunos de los temas sobre los que regularmente platicamos siempre están impregnados de la devoción de Julián por la academia, la educación y el conocimiento.

Julián ha contribuido a mi formación como persona y como profesionista; hoy en día lo considero un gran amigo y consejero. Pero, más que nada, un compañero con el cual disfruto al máximo de la conversación. Pláticas largas y deleitantes que se dan gracias al interés mutuo por las aportaciones del otro, con base en la pasión por las disciplinas que cada uno de nosotros ha decidido ejercer. Siempre mostrando interés por mis puntos de vista, Julián me ha motivado a mantener mis ideas acerca de la "filosofía de acción” y siempre ha aportado grandes propuestas para fundamentar mis ideas y así, en un futuro, poder plasmarlas en acciones.

\title{
EDUCÁNDONOS
}

Francesca Arienzo*

Teníamos una tarea fácil y sencilla: escribir un ensayo libre, de lo que quisiéramos y como quisiéramos. Parecía algo sencillo, pero cuando estaba frente a la hoja en blanco sin tener citas en las cuales apoyarme, la tarea empezó a ser más difícil.

*Abogada por el ITAM. 
ALUMNOS

Desde que entregué este trabajo no había tenido oportunidad de releerlo. Decidí escribir sobre la educación, ahora todo hace sentido. Mi ensayo decía así: Tengo que ser sincera, siempre es un gran problema empezar un ensayo. Sobre todo porque rara vez se tiene la opción de escoger un tema con plena libertad de escribir lo que uno piensa e imagina. Me he desacostumbrado a ello. Esta fue una de mis mayores enseñanzas en el ITAM.

Seguía así: No estaba segura de qué quería hablar. El tema de la educación siempre me ha llamado la atención, y aunque es un tema del que se ha hablado mucho, me parece que no siempre se ha tomado en serio. Es muy importante, ya que sus consecuencias pueden ser o muy benéficas o muy malignas, según lo que se entienda por educación. La educación implica un verdadero cambio en la persona y por eso conlleva una gran responsabilidad. Es parte del problema de establecer definiciones fijas y para siempre. Problema que en la actualidad se acelera. Me parece fundamental cuestionarse esos conceptos y fines que se dan por hechos, porque cuando algo se da por hecho, pierde su verdadero significado.

Buscando autores que hablaran del tema (no lo pude evitar) me encontré con un ensayo de Edgar Morin. Me pareció una excelente idea. "La mente bien ordenada". Al abrir la primera página, lo primero que veo es una invitación. Una invitación a recuperar las ganas para la enseñanza, para cuidar cada quien su propia educación.

El ensayo seguía así: El tema de la educación es fundamental en un paisaje en el que los individuos se encuentran cada vez con menos posibilidades de socialización, en una sociedad en la que el individualismo impera y en un mundo que nos presenta paisajes cada vez menos conmovedores. Paisajes que no aportan nada bueno a la vista y que, por el contrario, la cercenan. En un contexto así, la educación tiene en realidad muchos campos de acción que aprovechar. Me parece que si la educación no tiene un papel predominante en el escenario actual es porque no entendemos lo que realmente es. Deberíamos entenderla como ese espacio que queda libre para volver a ser personas y no máquinas, que pasan a ser parte de ese gran sistema que nos rodea. Al contrario, lo que deberían entender los educadores es que lo que se entiende por enseñar no es aprenderse cosas de memoria sin entender nada. Enseñar que la "educación” puede ser muy divertida. Que tiene 
como fin primordial a la persona. A la persona como fin en sí mismo y no como un medio para lograr ciertos fines.

Hay una distinción que muchas veces no se percibe entre formación e información, entre sabiduría y conocimiento, entre educación, en el sentido ya apuntado de especialización, y enseñanza.

Cuando escribí este ensayo para la clase de Julián, era mi segundo semestre. Lo leo y vuelvo a pensar en lo que me enseñó Julián. Hoy lo volvería a escribir. Hoy me sigue costando mucho trabajo escribir y pensar libremente; no logré quitar la cita de Morin en este texto. Habrá que seguir aprendiendo de Julián como profesor, como amigo, pero sobre todo como persona.

Como profesor, le agradezco por haberme educado, por haberme enseñado y por haberme hecho más sabia. Como persona, le agradezco enseñarme a tener ideas frescas, a divertirme en la vida y a tomármela con gracia. La amistad que hoy tenemos es muy importante para mí. Esas pláticas y cenas interminables han cambiado muchos de mis puntos de vista; otras veces los han afirmado y radicalizado. Pero Julián siempre está ahí para formarte, escucharte y divertirte. Ojalá muchas personas más tengan la oportunidad de entender qué es la educación desde su perspectiva.

\section{DE SU REBELDE PESIMISMO}

Natalia Reyes Heroles S.*

Julián Meza llega siempre unos minutos más tarde del horario establecido para su materia, tiempo suficiente para que, cuando entre, el salón esté lleno por completo. Se aproxima serio, muy serio, y entrega al primer alumno que encuentra una hoja blanca. Tiene la función de lista. Siempre me quedará la duda de saber

* Abogada por el ITAM. 